\title{
The Wonder of Empathy:
}

\author{
Using Palacio's Novel to Teach Perspective Taking
}

I

n the era of Common Core-driven curriculum

(National Governors Association Center for Best

Practices \& Council of Chief State School Officers, 2010), teachers face difficult decisions about how much time to dedicate to fiction. Amid perceived and real pressure to divert time to nonfiction, educators must consider the potential cost of such a trade. Today's measurement-driven educational climate may not leave room for character development, but even fictional educators recognize that it should. At the end of R. J. Palacio's middle grade novel Wonder (2012), Mr. Tushman, the school principal, explains the importance of an award he is about to give. (No spoilers here. If you want to know who wins, read the book.)

Courage. Kindness. Friendship. Character. These are the qualities that define us as human beings, and propel us, on occasion, to greatness. And this is what the Henry Ward Beecher medal is about: recognizing greatness. But how do we do that? How do we measure something like greatness? Again, there's no yardstick for that kind of thing. How do we even define it? (Palacio, 2012, p. 304)

The prosocial qualities Principal Tushman describes require empathy: the ability to recognize, understand, and share another's feelings. Measuring "greatness" may be problematic, but psychologists have developed tests for different aspects of empathy as well as a prerequisite skill-theory of mind-which includes the ability to interpret nonverbal cues and to distinguish one's own beliefs from another's. In recent years, psychologists have shown increased interest in the ability of narrative fiction to enhance both empathy and theory of mind, abilities nonfiction has never been shown to mimic (Kidd \& Castano, 2013; Mar, Oatley, Hirsch, de la Paz, \& Peterson, 2006; Mar, Oatley, \& Peterson, 2008). There is now strong empirical evidence for a long-held assumption of many teachers: reading fiction helps students develop socially as well as academically.

This emerging field of study can benefit from interdisciplinary collaboration between English teachers and psychologists. While psychologists can provide behavioral measures, teachers are best equipped to select appropriate books and activities that will most engage students. The growing body of research addressing fiction's impact on empathy can inform curricular choices, particularly when the issue of reducing time devoted to literature arises. Here we describe a collaborative research project by an English teacher from an independent school and an academic psychologist from a liberal arts college. The major finding was that sixth-grade students showed improved scores on a common psychological empathy assessment after completing an academic unit on Wonder.

\section{Empathy and Fiction: What Research Tells Us}

It is helpful to place the collaborative project in the context of recent psychological research. Reading fiction is hypothesized to simulate social contact in a way that minimizes anxiety, allowing reduction of prejudice and development of empathy (Johnson, Jasper, Griffin, \& Huffman, 2013b; Mar \& Oatley, 2009). Mar et al. (2006; 2008) found that frequent adult readers of fiction, but not nonfiction, had higher empathy 
and better theory of mind skills than less frequent readers.

Mental engagement with the story is necessary for empathy enhancement (Bal \& Veltcamp, 2013; Johnson, 2012; Johnson, Cushman, Borden, \& McCune, 2013a). There is also evidence that, in adults, improvements in empathy and theory of mind come more from "literary" fiction, defined as "writerly" fiction that actively engages the reader, than from "readerly" fiction that entertains passively (Kidd \& Castano, 2013). Whether that distinction is meaningful for younger readers is not known.

Ironically, even as evidence for fiction's empathyenhancing effects in adults mounts, a movement is underway to reduce the amount and variety of fiction studied in secondary school in favor of informational nonfiction reading (Bauerline \& Stotsky, 2012). If anything, fiction would be expected have a stronger prosocial effect on younger readers. Empathy skills, particularly concern for others and the capacity to readily take another's perspective, increase dramatically during adolescence (Hawk et al., 2013; Van der Graaf et al., 2014). Secondary school is also when students begin to learn literary analysis, a topic often introduced during the middle school years by the study of young adult literature (YAL; Bushman, 1997).

While schools have traditionally valued the study of literature for teaching language and reasoning skills (Bauerline \& Stotsky, 2012), there is now increasing evidence for additional social benefits of reading. Mar, Tackett, and Moore (2010) found that even for preschool-aged children, higher exposure to children's books was associated with better theory of mind, a finding that closely parallels the effects of fiction in adults. At least for adults, the positive impact of fiction on interpersonal skills is not duplicated with nonfiction (Kidd \& Castano, 2013; Mar et al., 2006; 2008).

\section{Reading Fiction Reduces Prejudice in Schoolchildren}

Teachers often select books with the goal of promoting prosocial behavior, but only rarely do they collaborate with behavioral scientists to collect empirical data and determine if the goal was met. To our knowledge, the adult correlational studies that show improved interpersonal skills with fiction but not nonfiction exposure (e.g., Mar et al., 2006; 2008) have not been repeated in school-aged readers. However, there have been at least three school-based studies on the capac- ity of reading assignments to increase compassion and reduce prejudice in young people.

After hearing and discussing a series of children's stories that positively portray characters with disabilities, British elementary schoolchildren expressed improved attitudes toward and an increased willingness to befriend disabled children (Cameron \& Rutland, 2006). In a second study, twelve-year-old Italian children who were given a summer reading assignment from a list of books with protagonists from other cultures showed less prejudice against immigrants than children who were given a comparable list of books without interdence for fiction's empathy-enhancing effects in adults mounts, a movement is underway to reduce the amount and variety of fiction studied in secondary school in favor of informational nonfiction reading.
Ironically, even as evicultural themes, or those who were given no assignment (Vezzali, Stathi, \& Giovannini, 2012).

In a third and well-publicized study in this field, Vezzali, Stathi, Giovannini, Capozza, and Trifiletti (2014) used a six-week experimental manipulation with 17 Italian fifth-grade students, exposing them to selected readings from the Harry Potter series (Rowling, 1998-2007) that were critical of prejudice and engaging the children in weekly discussions of the excerpts. A control group experienced readings and discussions about other wizardly topics like Quidditch and buying wands. Tests given before and after the intervention showed that readers who heard the anti-prejudice selections improved their attitudes toward a stigmatized group (immigrants) more than the controls, but only if they strongly identified with Harry. Vezzali et al. (2014) followed the experiment with fifth-graders with a larger correlational study of high school students and found that students who read more Harry Potter books and identified with Harry reported less prejudice towards homosexuals, even though sexual orientation was never addressed in Rowling's series. Unlike the fifth-graders, the high school students had presumably read the Harry Potter books in a more leisurely setting and did not experience the wizard-themed anti-bigotry lessons. 
Socializing in the Fictional Realm Eases Anxiety These three studies (Cameron \& Rutland, 2006; Vezzali et al., 2012; 2014) are based on the hypothesis that reading reduces prejudice through indirect social contact with a targeted group (Mar \& Oatley, 2009). Whereas real-life contact with an obvious outsider might be frightening, fiction provides simulated contact where a young person can "get to know" someone Could replacing fiction different in a safe setting. with nonfiction in the curriculum harm empathy development and increase antisocial behavior? Long-term prejudice reduction requires learning to adopt a target's viewpoint. Vezzali et al. (2014) also found that college students who had read more Harry Potter books and rejected identification with Voldemort reported less prejudice against refugees and were more likely to agree with perspective-related statements like "It is easy for me to jump into a refugee's shoes."

Other school-based programs use popular YAL as a tool to enhance social acceptance and reduce bullying, but empirical evidence of their effectiveness is often lacking (e.g., Hebert \& Kent, 2000; Hillsberg \& Spak, 2006). The debate over the place of literary study in the curriculum raises multiple questions: Do adolescents show the same empathetic responses to fiction, but not nonfiction, as adults? Is the distinction between "popular" and "literary" fiction meaningful to younger students? Can teachers use the same popular YAL students choose for themselves not only to teach literary skills but also to promote empathy? Could replacing fiction with nonfiction in the curriculum harm empathy development and increase antisocial behavior? Such questions are best addressed by collaborative efforts between educators and behavioral scientists to both design appropriate curricula and evaluate their effectiveness.

\section{The Current Study}

\section{Plot Synopsis}

Wonder enjoyed 115 weeks on the New York Times bestseller list and appeared on both the School Library Journal's Best of Children's Literature and Publishers Weekly Best of Children's Books lists in 2012. Its protagonist, a fifth-grade boy named Auggie, has been home-schooled his entire life because of profound cranio-facial deformities and the surgeries he required. Auggie's parents decide that the first year of middle school is a good time for him to begin attending school at Beecher Prep. Auggie is anxious about other students' reactions to his face.

Mr. Tushman, Beecher Prep's principal, arranges for three students to meet Auggie before the school year begins: Jack, Charlotte, and Julian. In Mr. Tushman's eyes, these are welcoming, kind students. It doesn't take long, however, to figure out that Julian's behavior fails to match adults' perceptions. Throughout the novel, he bullies Auggie in ways both subtle and overt.

Jack finds himself sitting next to Auggie in each class, and while he resents this at first, eventually he gets to know Auggie, and the two develop a friendship. Nevertheless, under pressure from other students, Jack says hurtful things about Auggie, not realizing that Auggie is overhearing. Auggie is devastated and wants to leave school. Jack and Auggie are able to mend their relationship, but as a result, Julian begins to victimize Jack along with Auggie.

Happily, Julian's bullying campaign does not succeed. In the end, while on a class nature retreat, several of Auggie's classmates demonstrate support for him by defending him against older students from another school who verbally and physically attack Auggie because of his unusual appearance. Although his condition will clearly continue to challenge him, Auggie finds acceptance from his peers.

\section{Rationale and Aims}

\section{WHY WONDER?}

Wonder was chosen for several reasons. First, it is written on a fifth-grade reading level, making it easily accessible to our sixth-grade students as the first book of the school year. Second, its setting, Beecher Prep, a selective and expensive private school that provides need-based aid to lower-income children, shares some similarities with our own school, the Episcopal School of Baton Rouge. Third, we thought that Auggie's anxiety about fitting in with new peers would resonate with our students. Approximately $30 \%$ of the sixth-grade students were new to Episcopal, creating the potential for bewilderment as new social groups formed. Fourth, Wonder is told from various perspec- 
tives. The story features the voices of five characters other than Auggie, all with their own conflicts, offering multiple opportunities for students to empathize with characters. While Auggie is the obvious, visible outsider, other characters also struggle with wanting to fit in and be accepted. Last, Palacio's goal in writing the book was to promote empathy, which she calls "the antithesis of bullying" (Walsh, 2013, p. 1). Our collaboration provided an opportunity to see whether or not the author succeeded.

\section{The STudy's Goals}

The purpose of the present study was to determine if reading Wonder, combined with related classroom activities on characterization, perspective, and empathy, could increase empathy. Rather than evaluate changes in specific prejudice, as did Cameron and Rutland (2006) and Vezzali and colleagues (2012; 2014), we used a more general empathy test. Auggie's medical condition is rare; most students will never encounter anyone with the same level of facial deformity. However, if compassion for Auggie generalizes to anyone whose differences make them the target of bullying, nonspecific empathy skills should increase.

\section{A Collaborative Effort}

This research was a joint endeavor of an English teacher, Martha Guarisco, who designed and implemented the lesson plans; a guidance counselor, Alicia Kelly, who led the class through empathy-building activities; and a psychology professor, Louise Freeman, who arranged the computer-based empathy testing and analyzed the data. The collaboration arose from the First Annual Young Adult Literature Conference and Symposium, held at Louisiana State University in June 2014, where Guarisco and Freeman met and discovered their mutual interest in the effects of fiction on empathy.

\section{Method}

\section{Participants}

Participants were 80 sixth-grade students (38 male, 42 female) from Episcopal School of Baton Rouge, Louisiana, an independent school with one of the highest tuitions in the city. Twenty-two percent of students receive need-based financial aid. Parents of the participants gave informed consent for participation, while the students gave written assent. The school principal gave permission for the study, and the Institutional Review Board of Mary Baldwin College (Staunton, VA) approved all survey procedures.

\section{Procedure}

\section{Empathy Pre-assessment}

The Wonder academic unit began in September 2014 and lasted for 5-6 weeks. Before reading began, we administered the Interpersonal Reactivity Index (Davis, 1983), a well-characterized and validated measure of general empathic tendencies. It contains 28 statements scored on a 5 -point scale $(1=$ not at all like me, $5=$ very much like me). Seven items measure interpersonal reactivity for four subscales: Empathic Concern (feelings of sympathy and concern for others in distress); Perspective Taking (the tendency to adopt another's point of view); Personal Distress (the tendency to share another's pain or distress); and the Fantasy Scale (the tendency to transport oneself mentally into fictional works). Sample items include:

- I often have tender, concerned feelings for people who are less fortunate than me (Empathic Concern).

- Before criticizing people, I try to imagine how I would feel if I were in their place (Perspective Taking).

- I sometimes feel helpless when I see people in the middle of a very emotional situation (Personal Distress).

- When I am reading a good story or novel, I imagine how I would feel if the events in the story were happening to me (Fantasy Scale).

We made minor adaptations in the original Interpersonal Reactivity Index to make the reading level more age-appropriate. Students completed the Interpersonal Reactivity Index on school computers using the Qualtrics survey system. To assure anonymity, they chose code names for themselves and were instructed to use the same code on the assessments before and after the unit so that individual changes could be measured. Students were also asked their gender and whether they had read Wonder prior to the school assignment.

\section{Characterization and Literary Perspective}

Before they started reading, students were placed into random groups of four and assigned a particular 
character to "watch" over the course of the novel. As they read the text, they marked sections that revealed something about the character they had been assigned: a physical description; the reaction

The students' PerspectiveTaking scores showed a small but statistically significant (5.8\%) increase after the unit, compared to their initial score. The other empathy subscales did not change significantly. This suggests that after the unit, students saw themselves as more readily adopting others' psychological viewpoints. of another character; or something the character revealed through dialogue, thought, or action.

To highlight the complexity of the novel's characterization, students did close readings of two chapters that show the same scene-Auggie cutting off a braid he had been growing for years-from two different perspectives, that of Auggie and his highschool-aged sister Via. The student groups considered characters' actions and underlying emotions. They examined the roles of Auggie, Via, and their mother, compiling their analysis on

a chart and determining which components the three characters would have

known about at the time. They concluded that characters would have knowledge about each other's emotions only if there had been some dialogue about them.

\section{Responsive Writing}

Before students began the novel, they wrote a fiveminute response to a prompt asking them to define what "normal" meant to them, then shared and discussed the responses. After defining normal, students wrote a longer, multi-paragraph piece on how they defied normal, exploring the question: What makes you unique from your peers?

Throughout Wonder, Auggie's English teacher, Mr. Browne, gives his students "precepts" as writing prompts. He explains the precepts as words to live by, or guiding principles. He asks his students to choose their own precept and send it to him on a postcard over the summer. Our students used some of $\mathrm{Mr}$ Browne's precepts as writing prompts during the unit.
They also used the iPad Brushes application to create self-portraits mimicking the novel's artistic style. At the end of the unit, they selected their own personal precept, attached it to their self-portraits, and shared with the class on a website.

Another responsive writing assignment addressed a sensitive issue within our own school. Auggie's friend Jack is a scholarship student who, in one scene, feels stigmatized by his wealthier classmates. Before reading this chapter, students responded to a writing prompt that we hoped would help them better understand Jack's perspective: "Does class matter at Episcopal?" Following the writing, they engaged in discussion.

\section{Empathy Training Exercise}

About two weeks after beginning the book, the students participated in an activity with middle school guidance counselor Alicia Kelly on empathy and perspective. They traced their shoe on a piece of paper and wrote a few descriptors (physical traits, favorite activities) of themselves on the opposite side. Students placed their shoe outlines around the room and followed a set of verbal instructions to move to and stand on a new set of shoes. Based on criteria the counselor announced, students tried to guess in whose shoe they were standing.

The guidance counselor tied the activity into Wonder by explaining how little students can know of a person by a physical trait like shoe size. Because students were reading a section told from Via's perspective, she asked them to generate a list of emotions that Via was feeling. Like Auggie, Via is also a new student in her school and is struggling to find her place as her friendship group shifts. The counselor emphasized that it is normal to feel sad and hurt when excluded. She ended the lesson with video clips about kindness and had students think of ways they could show kindness in their daily lives at school.

\section{Literary Analysis}

Throughout the unit on Wonder, lessons focused on the "writerliness" of the novel, especially on Palacio's use of allusions and idiomatic phrases. Students became familiar with common literary terms, such as setting, conflict, and characterization. Their culminating evaluation, completed in their original groups, was to create and present a "character-in-a-bag" that 
included an illustration of the assigned character, evidence to support whether the character was static or dynamic, three important quotations, and descriptions of conflicts that the character faced. Inside the bag, they included ten objects that somehow represented the character.

Most literary activities were typical for a language arts classroom and were designed to help students build comprehension and analysis skills. Aside from the special lesson by the guidance counselor, the main empathy-building exercise was directing students to look at the story from a given perspective. The structure of the novel guided students as they read; additional support came from the focused highlighting and note taking students did in their groups.

\section{Final Empathy Assessment}

About one week after reading was finished, during the week of the final group projects, students took the Interpersonal Reactivity Index again. We hypothesized that one or more of the empathy subscale scores would increase from the first to the second test session.

\section{Data Analysis}

The effects of gender, prior book exposure, and changes in empathy between the first and second tests were evaluated by mixed-design analysis of variance, followed by post-hoc testing. Relationships between gender and prior book exposure were evaluated by a Chi-square test for independence.

\section{Results}

Thirteen students failed to complete both surveys or provided non-matching codes, leaving 67 participants (32 males, 35 females). Fifteen students (3 males, 12 females) had read Wonder prior to the class assignment, with girls significantly more likely to have read the book than boys.

The students' Perspective-Taking scores showed a small but statistically significant (5.8\%) increase after the unit, compared to their initial score. The other empathy subscales did not change significantly (see Table 1). This suggests that after the unit, students saw themselves as more readily adopting others' psychological viewpoints. There were no differences between males and females on any empathy measure.

Students who had previously read Wonder scored higher on the Fantasy Scale for both sessions (see
Figure 1). Prior exposure to the book made no difference in any other Interpersonal Reactivity Index measure. Prior readers showed the same specific gains in Perspective Taking as young people who had not previously read the book.

\section{Discussion}

\section{Confirmation of Hypothesis}

Our prediction that the Wonder unit would enhance empathy was confirmed. Since the effect was specific

Table 1. Exposure to Wonder is associated with higher average scores on perspective taking in young readers.

\begin{tabular}{|l|c|c|c|}
\hline IRI Subscale & Before Wonder & After Wonder & Change in Score \\
\hline Empathic Concern & $26.72 \pm 0.545$ & $26.42 \pm 0.619$ & $-1.1 \%$ \\
\hline Perspective Taking & $21.40 \pm 0.569$ & $22.64 \pm 0.545$ & $+5.8 \% *$ \\
\hline Personal Distress & $19.57 \pm 0.591$ & $20.10 \pm 0.577$ & $+2.7 \%$ \\
\hline Fantasy Scale & $19.75 \pm 0.583$ & $20.61 \pm 0.606$ & $+4.35 \%$ \\
\hline
\end{tabular}

*Significant increase in second test session, $p=0.01$. Scores are given as means $+/$ - standard error of the mean.

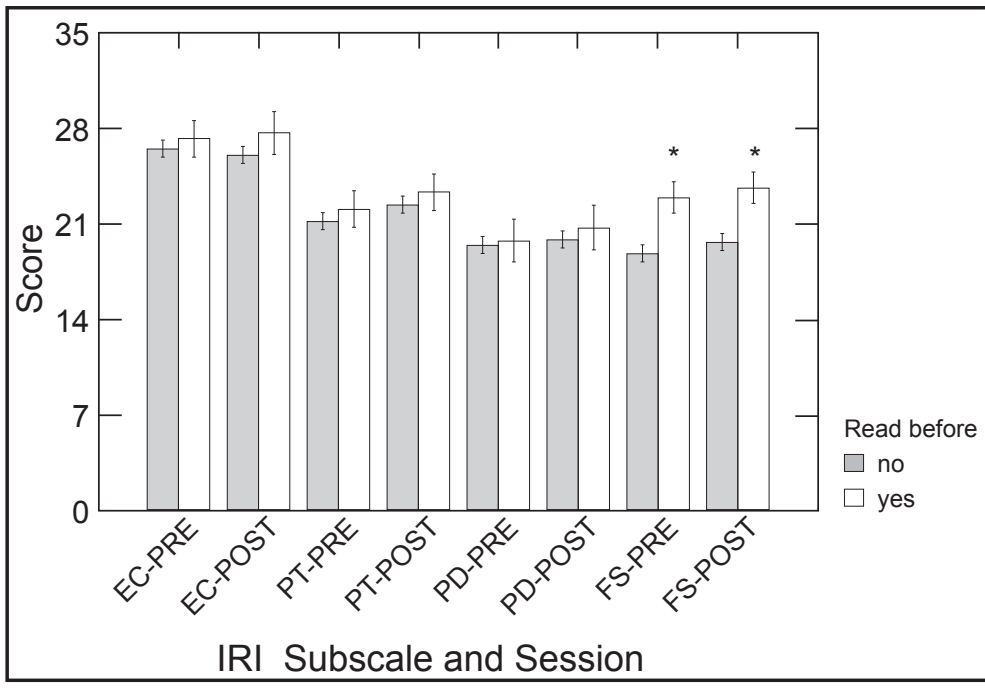

* Students who had previously read Wonder had higher Fantasy Scale scores before and after the Wonder unit. Of the four empathy scales measured, only the Fantasy Scale (FS) was significantly different in students who had previously read the book $(\mathrm{N}=15)$ and those who had not $(\mathrm{N}=52)$. Prior reading did not reduce the benefits of studying Wonder in school; prior readers showed an increase in Perspective Taking comparable to nonreaders. EC = Empathic Concern; PT $=$ Perspective Taking; PD = Personal Distress. Error bars indicate standard errors of the mean.

Figure 1. Pre- and post-reading statistics for four empathy scales.* 
for only one of the four subscales, it is likely that these young people genuinely perceived themselves as better perspective takers. If students had tried to please the teacher by giving "nicer" answers on the second session, we would have expected increases in all of the subscales.

\section{Generalized Empathy}

Our study differed from previous school-based studies in the way we measured empathy. The Interpersonal Reactivity Index is a multipurpose scale that targets no specific group. Earlier studies on reading and prejudice reduction in young people (Cameron \& Rutland, 2006; Vezzali et al., 2012; 2014) measured readers' attitudes toward members of specific marginalized groups. Only the Vezzali et al. 2014 study on the Harry Potter series specifically measured perspectivetaking skills, but that research was limited to college students and a more specific survey about the viewpoints of refugees rather than the Interpersonal Reactivity Index. To our knowledge, ours is the first study that connects young reader's exposure to fiction with improved skills in adopting the psychological perspective of others. Such nonspecific empathy is probably necessary if compassion for a specific fictional group is going to extend to other groups, as in the case of the Harry Potter books (Vezzali et al., 2014).

\section{Empathy Enhancement Specific to Perspective Taking} Given Wonder's emphasis on different character viewpoints, it is not surprising that Perspective Taking was the empathic trait that specifically increased. Other studies using the Interpersonal Reactivity Index have also found that fiction-induced enhancement of empathy is limited to Perspective Taking. Stansfield and Bunce (2014) used three of the Interpersonal Reactivity Index subscales (Empathetic Concern, Perspective Taking, and Personal Distress) as a pretest before exposure to a story. They found that Perspective-Taking scores, but not the other two subscales, were higher in the more frequent readers. Pilot data recently collected at Mary Baldwin College found that students who had read all seven Harry Potter novels had higher Perspective-Taking and Fantasy Scale scores than students who had read four or fewer; Empathic Concern and Personal Distress did not differ (Freeman, 2015, unpublished).

Other contemporary YA novels also use multiple points of view; examples are listed in Table 2. These

Table 2. Other middle grade and young adult novels written from multiple perspectives

\begin{tabular}{|l|l|l|l|}
\hline Title & Author & Publisher & Published \\
\hline American Born Chinese & Gene Luen Yang & Square Fish & 2006 \\
\hline A Fast and Brutal Wing & Kathleen Jeffrie Johnson & Square Fish & 2004 \\
\hline Eleanor \& Park & Rainbow Rowell & St. Martin's Griffin & 2013 \\
\hline Jellicoe Road & Melina Manchetta & HarperTeen & 2010 \\
\hline Keesha's House & Helen Frost & Square Fish & 2013 \\
\hline My Most Excellent Year & Steve Kluger & Speak & 2009 \\
\hline Poison Ivy & Amy Goldman Koss & Square Fish & 2006 \\
\hline Real Time & Pnina Moed Kass & HMH Books for Young Readers & 2004 \\
\hline Sisterhood of the Traveling Pants & Ann Brashares & Ember & 2001 \\
\hline Witness & Karen Hesse & Scholastic Paperbacks & 2003 \\
\hline The Year of Secret Assignments & Jaclyn Moriarty & Scholastic Paperbacks & 2004 \\
\hline
\end{tabular}


books represent a wide range of content and style; what they have in common is how easily they could be used to help students examine perspective.

\section{Fiction And Theory of Mind}

Multiple researchers have found that reading fiction also enhances a trait necessary in adopting another's perspective: theory of mind, or the ability to discern the emotions, beliefs, and intentions of others. Tests for theory of mind skills typically involve determining a participant's emotional state through observation of his/her eyes or facial expressions or identifying the effects of another's false beliefs. Mar et al. (2006; 2008) and Djikic, Oatley, and Moldoveaunu (2013) administered author name recognition tests for fiction and nonfiction writers, along with different theory of mind tests. Theory of mind abilities correlated positively with recognition of fiction writers, but not nonfiction writers, suggesting that higher theory of mind scores were associated with lifetime exposure to fiction, but not to nonfiction. Kidd and Castano (2013) replicated that finding on some, but not all, of their correlational studies; Stansfield and Bunce (2014) failed to find such a relationship but used a much smaller sample size.

Kidd and Castano (2013) also found that a brief session of reading literary fiction, but not nonfiction or popular fiction, was also associated with an increase in theory of mind scores. Interestingly, one of the traits Kidd and Castano used to define "literary fiction" was the presentation of multiple perspectives. While some might scoff at labeling a novel written on a fifth-grade level as "literary," ${ }^{1}$ Wonder uses multiple narrators and depicts the same events from different points of view at a reading level appropriate for middle school readers. While we did not measure theory of mind skills explicitly in our students, the task that asked students to chart different emotions to determine what one character knew about another's emotional state and how and when they learned it might be considered specific training in theory of mind skills.

1. Vezzali et al. (2014) argue that the Harry Potter series also meets the definition of literary fiction, so children's and young adult books do not seem to be automatically excluded from this category.

\section{Possible Reasons for the Wonder Unit's} Effectiveness

Simulation of Social Contact

According to the indirect social contact hypothesis

(Mar \& Oatley, 2009; Vezzali et al., 2012), reading

about Auggie allowed students to "meet" a child very

different from themselves

in the safe arena of fiction.

An in-person encounter

with someone as disfig-

ured as Auggie might

have produced significant discomfort in sixth graders; in the fictional world, they experienced contact with him vicariously, while also getting an inside look at the hurt Auggie feels when people react negatively to his appearance. At the same time, seeing the perspectives of other characters showed students they are not alone in their
Several activities in the

Wonder academic unit incorporated specific elements that past research suggests would increase the intensity of simulated social contact and thereby enhance the book's capacity to induce empathy. possible discomfort; even

Auggie's sister at times feels awkward around him.

Beyond the indirect contact reading provided in itself, several activities in the Wonder academic unit incorporated specific elements that past research suggests would increase the intensity of simulated social contact and thereby enhance the book's capacity to induce empathy.

\section{Time Allowed for Effects}

The Wonder unit lasted 5-6 weeks, similar to other school-based studies in prejudice reduction (Cameron \& Rutland, 2006; Vezzali et al., 2012; 2014). Although some studies (e.g., Djikic et al., 2013; Johnson, 2012; Johnson et al., 2013a; Kidd \& Castano, 2013) found immediate enhancement of empathy by a short reading, Bal and Veltkamp (2013) found it took a week after the reading experience for empathy to rise, implying that a clear memory of and reflection on the fiction was necessary. This "sleeper effect" is one that teachers need to acknowledge. It takes time for students to process what they have read and for the story to affect them in positive ways. Although our increase in Perspective Taking was small, it was present a 
week after reading was completed and 3-4 weeks after the guidance counselor-led perspective exercise.

Drawing the Readers into the Novel

Wonder was specifically chosen because of the potential for students to identify with the protagonists.

The assignments to illustrate a Wonder character and create a character bag required the students to both visualize the character physically and consider objects the character might use or encounter frequently. This exercise might have generated meaningful imagery and enhanced mental transport into Wonder. Effective books induce strong identification with characters and emotionally transport readers into the story; for example, Vezzali et al. (2014) found that prejudice reduction in school-aged students required strong identification with Harry Potter. Some of our exercises were designed to make the students feel like they were Auggie's classmates. By following an assigned character, our students were asked to "get to know" the character much as Jack, Charlotte, and Julian were asked to befriend Auggie. Writing responses to Mr.

Browne's precepts, as if they were in English class with Auggie, also likely helped to mentally transport the students into Auggie's world.

Our results are consistent with those of studies with adults (Bal \&Veltcamp, 2013; Johnson 2012; Johnson et al., 2013a; Stansfield \& Bunce, 2014) that found that fiction-induced empathy requires active engagement with the story. Johnson et al. (2013a) reported that training in imagery generation (imagining objects or events in multiple sensory modalities) increased emotional transport into the story more than focusing on the meaning of words or reading a story without instruction. The assignments to illustrate a Wonder character and create a character bag required the students to both visualize the character physically and consider objects the character might use or encounter frequently. This exercise might have generated meaningful imagery and enhanced mental transport into Wonder.

As illustrated by the Harry Potter series (Vezzali et al., 2014), a story does not have to be realistic to engage readers, but readers do have to suspend their disbelief. Bal and Veltkamp (2013) found that if a reader was not transported into the story, empathy levels could actually decrease with reading. Teachers must help students become drawn into the story and pace instruction so that students maintain their enthusiasm. Additionally, teachers bear responsibility in making effective text selections for students, which requires that teachers know their readers. A text that is too difficult or complex or one in which readers cannot identify with the conflict or characters may fail to engage students.

\section{An Appropriate Age}

Fiction is particularly useful in increasing Perspective Taking in adults who are lower in that tendency at the onset. Djikic et al. (2013) implemented a similar but shorter-term study than ours, measuring Empathetic Concern and Perspective Taking immediately before and after reading a short story. Like us, they found increases only in Perspective Taking and only in participants who started with lower Perspective-Taking scores. Those with higher beginning PerspectiveTaking scores may not have had as much room for measurable improvement.

Similarly, Johnson et al. (2013b) found that narrative fiction reduced prejudice against Arab Muslims only in individuals with low beginning PerspectiveTaking scores, suggesting that people who do not readily take the viewpoint of others benefit more from fictional social encounters. If fiction is most influential in people with lower Perspective-Taking skills, it would be expected to be particularly effective in younger adolescents, whose empathic skills are developing and who have lower Perspective-Taking scores than older teens and adults (Hawk et al., 2013; Van der Graaff et al., 2014).

\section{Gender and Prior Experience}

Interestingly, we found no significant differences between boys and girls on any Interpersonal Reactivity Index subscale. By age 13, girls typically have higher Interpersonal Reactivity Index scores than boys, and 
differences increase as young people mature (Hawk et al., 2013; Van der Graaff et al., 2014). We likely failed to see a gender difference in empathy either because our students were younger (10-12) or because of our smaller sample size. However, Vezzali et al.’s Harry Potter series study (2014) showed that fifth-grade girls were less likely to stigmatize immigrants than boys, even with a fairly small sample (13 males, 21 females). It is also possible that gender differences in prosocial traits are more obvious in specific reactions to others than in the more general Interpersonal Reactivity Index measures.

Although Wonder features a male protagonist, girls were more likely to have read the book prior to the school unit. Even though prior readers were a small subsample (15/67 participants), students who had read Wonder previously had significantly higher Fantasy Scale scores in both the first and second empathy inventories. The Fantasy Scale may be a measure of how much one enjoys fiction (Nomura \& Akai, 2012). The simplest explanation is that those who had read Wonder independently were more voracious and enthusiastic readers than their classmates.

It is important to note that students who had previously read Wonder were not higher on Empathetic Concern, Perspective-Taking, or Personal Distress scores at the start of the study and showed the same increase in Perspective Taking after the classroom experience as the other students, suggesting that neither specific exposure to Wonder nor their general reading habits reduced the benefits of studying the book in school. While we should avoid generalization based on this small sample, in this case, explicit study, not just the independent reading of Wonder, was necessary to increase Perspective Taking. This is consistent with Johnson et al.'s (2013a) finding that participants instructed to read a story as they would for leisure did not experience increases in emotional transport, empathy, or prosocial behavior.

\section{Does Higher Empathy Lead to Better Behavior?}

One weakness of our study is that we measured empathy only by the students' self-reports; we collected no data on any behavioral changes. Though the ability to empathize by adopting another's viewpoint is important in reducing both bullying and prejudice (Hillsberg \& Spak, 2006; Vezzali et al., 2014), we have no direct evidence that the improved Perspective-Taking scores led to more kindness in the classroom. However, other studies suggest that emotional engagement with fiction leads not just to higher empathy, but also to real-world kindness. Johnson et al. used willingness to either assist the researcher in picking up "accidentally" dropped pens (2012) or to participate in a new professor's 20-minute psychology survey for payment of only $\$ 0.05$ when higher-paying studies were available (2013a) as measures of helping behavior. Those with higher story-induced empathy and emotional transport were more likely to help and were more sensitive to nonverbal cues that signal a need for help.
While we should avoid generalization based on this small sample, in this case, explicit study, not just the independent reading of Wonder, was necessary to increase Perspective Taking.
Similarly, Stansfield and

Bunce (2014) reported that, after reading a fictional story about an African orphan, people with higher Fantasy Scale scores and higher story-induced affective empathy were more likely to request information about helping real orphans.

\section{Student Reactions}

We have anecdotal evidence for positive responses to the activities in the Wonder unit. In the first writing assignment, the majority of students offered descriptions of themselves as the definition of normalcy. For example, one girl who is herself a dancer wrote that a normal person "does sports such as if it was a girl dance and a boy football.” A particularly lively discussion stemmed from the suggestion that a normal sixth-grade boy played multiple sports. "What about the kids who don't?” asked one student. “They're still normal." Another posed a question about which sports were normal. If the athlete played lacrosse, a sport that isn't yet common in Louisiana, was that still normal? Students continued to widen their defining terms. Ultimately, they collectively agreed that there is no such thing as a normal sixth-grader and that terms like "average" or "typical" would be easier to define.

After the empathy exercise, students placed their ideas for showing kindness on a "Choose Kind" poster. One student wrote, "If someone is sitting by 
themselves, go and sit with them." This could be seen as a way that the student was relating to Auggie; finding companions in the school cafeteria was one of Auggie's biggest concerns. Another student posted, “Invite people that you don't know well to your house so you can get to know them better." This provides an-

Our findings demonstrate the usefulness of collaborative work between educators and behavioral scientists. other connection to Auggie; it is when he is invited to his classmates' homes that his friendships begin to blossom.

In response to the writing prompt about class differences, students were quick to identify the role that class and money play in their social world. One girl wrote: "I realize the one thing most people would do anything for: money. So, not being as rich as other people might [make them] think of you as a social outcast." Another boy recognized an important aspect of class at the end of his response:

People in poverty don't even have enough money for food. If they can't pay for food then they can't pay for education. Say you got a scholarship. You would still have to pay fees. Most people who go to Episcopal have lots of power.

Discussion after this assignment was clearly uncomfortable territory, with extra squirminess and wideeyed glances around the room. Despite the difficult conversation, it was important for students to understand the role that class conflict plays in Jack's character development as a scholarship student. Teachers will sometimes have to shepherd students through difficult territory; providing a safe environment is important in facilitating honest discussion.

Finally, the students' personal precepts reflected both creativity and compassion. Quotations came from diverse sources-from Ernest Hemingway to Vince Lombardi to Katy Perry. Some found their inspiration in Wonder itself, taking its message, "Choose Kind," to heart. One girl rewrote the message, making it her own, "My precept is 'Never forget the little parts of kindness in life.' . . . Kindness should be a rule of life, to always be kind. Also to remember the kindness people gave to you and that you gave to them."

One boy concluded with a quotation from his character-in-a-bag assignment:
I chose Charlotte Cody's precept from Wonder, "It's not enough to be friendly, you have to be a friend," because that's how I live and feel. It means that it isn't enough to just go and check on somebody to make sure they're okay. You actually have to mean it.

\section{Directions for Future Research}

Our findings demonstrate the usefulness of collaborative work between educators and behavioral scientists. There are many reasons for keeping literature as the centerpiece of secondary English classes: building vocabulary, stimulating analytical thinking, enhancing language skills, and boosting college preparedness (Bauerlein \& Stotsky, 2012). But psychologists can provide another: evidence for narrative fiction's empathypromoting effects-an ability that, at least in adults, is not shared with nonfiction (Mar et al., 2006).

If the capacity for empathy development is going to be used to defend the continued emphasis on literary fiction in English classes, more collaborative research is needed. It is essential that other books be evaluated for their ability to promote prosocial attitudes in order to determine whether empathy enhancement is a general characteristic of quality fiction or limited to certain types. Does a novel have to be told from multiple perspectives or carry an explicit pro-acceptance message to be effective? Must specific types of classroom exercises supplement the reading for maximum benefit?

Another urgent need is to determine whether nonfiction fails to enhance empathy and theory of mind skills in school-aged children, as it does in adults. This question could be addressed by a before-and-after administration of the Interpersonal Reactivity Index in conjunction with a collaboration between a behavioral scientist and a teacher doing a comparable 5-6 week unit using a collection of nonfiction titles. Alternatively, correlational studies of empathy measures or theory of mind tests with age-appropriate author or book recognition tests for fiction and nonfiction could be conducted in young readers as they have been for adults and preschoolers (e.g., Mar et al., 2006; 2008; 2010). Psychologists would undoubtedly need help from teachers and librarians in designing and validating such tests.

Psychologists have other measurement tools that could be useful in determining the mechanisms through which fiction exposure enhances empathy and which other mental processes might also be af- 
fected. It would be interesting to know if an academic unit on a multi-perspective novel can improve theory of mind in middle grade and high school students and if factors like emotional transport into the story or identification with characters are necessary to improve Perspective Taking. Again, collaborative efforts between psychologists and educators are needed to design and carry out such studies.

\section{Conclusion}

Palacio's Wonder provided a successful start to the school year because of its accessibility, rich character development, and themes. Its message to "choose kindness" helped set the tone for a safe learning environment. The classroom activities for the unit were specifically designed to cultivate imagery, engage the students with the characters and story, and introduce the concept of perspective in both a literary and psychological sense. When used with students at an age appropriate for the cultivation of empathy skills, the result was a significant increase in Perspective-Taking scores by the end of the unit. While the explicit message of Wonder may be to show kindness to people with physical differences, it appears that, with the right exercises, the result is improvement in nonspecific empathy skills needed for generalization of compassion to a wider social circle.

Atticus Finch taught his daughter Scout, "You never really understand a person until you consider things from his point of view . . . until you climb into his skin and walk around in it” (Lee, 1960, p. 39). He also read to her nightly, until reading became as natural to her as breathing, despite the Maycomb County education system's best efforts to squelch her enthusiasm. Modern research suggests a powerful connection between engagement with fictional worlds and the ability to see through another's eyes-a connection that teachers, parents, and policy makers would be wise to keep in perspective. In a 2013 panel sponsored by the Harvard Graduate School of Education, Palacio remarked, "Empathy is something that is very difficult to teach, but it is something that can be inspired in children” (Walsh, 2013, p. 1). Whether through the inspiring story of Auggie, the classroom teaching that accompanies the reading, or a combination of both, Palacio's novel can help children see things from another's point of view, an essential component of empathy.

\section{Acknowledgements}

The authors thank Alicia Kelly for the empathy-building classroom activities and student Nicole Pace of Mary Baldwin College for assistance with data entry.

Martha Stickle Guarisco earned her BA in English Literature and MEd in English Education from Louisiana State University. She is a National Board Certified Teacher in Early Adolescent English Language Arts and has spent 20 years working with middle school students. She is a writing instruction consultant, providing staff development workshops focused on writing across the curriculum. She enjoys young adult literature and finds great reward in being able to put the right book into the right reader's hands.

Louise M. Freeman received her BS in Biology from Emory University and her MA and PhD degrees in Biological Psychology from the University of California at Berkeley. She is currently a Professor of Psychology at Mary Baldwin College, where she has served as department head and chair of the School of Science. While her primary research interest is in the field of hormones and behavior, she also has an interest in psychological themes and personality influences in young adult literature. She has been a workshop leader at the Louisiana State University 2014 Young Adult Literature Conference and Symposium, a three-time guest on Mugglenet Academia, and a regular blogger on www.hogwartsprofessor.com.

\section{References}

Bal, P. M., \& Veltkamp, M. (2013). How does fiction reading influence empathy? An experimental investigation on the role of emotional transportation (Report \# e55341). PloS ONE, 8(1).

Bauerline, M., \& Stotsky, S. (2012, September 28). How Common Core's ELA standards undermine college readiness. Retrieved from http://pioneerinstitute.org/download/howcommon-cores-ela-standards-place-college-readiness-at-risk.

Bushman, J. H. (1997). Young adult literature in the classroomOr is it? English Journal, 86(3), 35-40.

Cameron, L., \& Rutland, A. (2006). Extended contact through story reading in school: Reducing children's prejudice toward the disabled. Journal of Social Issues, 62, 469-488.

Davis, M. H. (1983). Measuring individual differences in empathy: Evidence for a multidimensional approach. Journal of Personality and Social Psychology, 44, 113-126.

Djikic, M., Oatley, K., \& Moldoveanu, M. C. (2013). Reading other minds: Effects of literature on empathy. Scientific Study of Literature, 3, 28-47.

Hawk, S. T., Keijsers, L., Branje, S. J., Graaff, J. V. D., Wied, M. D., \& Meeus, W. (2013). Examining the Interpersonal Reactivity Index (IRI) among early and late adolescents and their mothers. Journal of Personality Assessment, 95, 96-106. 
Hebert, T. P., \& Kent, R. (2000). Nurturing social and emotional development in gifted teenagers through young adult literature. Roeper Review, 22, 167-171.

Hillsberg, C., \& Spak, H. (2006). Young adult literature as the centerpiece of an anti-bullying program in middle school. Middle School Journal, 38(2), 23-28.

Johnson, D. R. (2012). Transportation into a story increases empathy, prosocial behavior, and perceptual bias toward fearful expressions. Personality and Individual Differences, 52, 150-155.

Johnson, D. R., Cushman, G. K., Borden, L. A., \& McCune, M. S. (2013a). Potentiating empathic growth: Generating imagery while reading fiction increases empathy and prosocial behavior. Psychology of Aesthetics, Creativity, and the Arts, 7, 306-312.

Johnson, D. R., Jasper, D. M., Griffin, S., \& Huffman, B. L. (2013b). Reading narrative fiction reduces Arab-Muslim prejudice and offers a safe haven from intergroup anxiety. Social Cognition, 31, 578-598.

Kidd, D. C., \& Castano, E. (2013). Reading literary fiction improves theory of mind. Science, 342(6156), 377-380.

Lee, H. (1960). To kill a mockingbird. New York, NY: J. B. Lippincott.

Mar, R. A., Oatley, K., Hirsch, J., de la Paz, J., \& Peterson, J. B. (2006). Bookworms versus nerds: Exposure to fiction versus non-fiction, divergent associations with social ability and the simulation of social worlds. Journal of Research in Personality, 40, 694-712.

Mar, R. A., Oatley, K., \& Peterson, J. B. (2008). Exploring the link between reading fiction and empathy: Ruling out individual differences and examining outcomes. Communications, 34, 407-428.

Mar, R. A., \& Oatley, K. (2009). The function of fiction is the abstraction and simulation of social experience. Perspectives on Psychological Science, 3, 173-192.
Mar, R. A., Tackett, J. L., \& Moore, C. (2010). Exposure to media and theory of mind development in preschoolers. Cognitive Development, 25, 69-78.

National Governors Association Center for Best Practices \& Council of Chief State School Officers. (2010). Common core state standards for English language arts and literacy in history/social studies, science, and technical subjects. Washington, DC: Author. Retrieved from http://www.corestandards .org/ela-literacy.

Nomura, K., \& Akai, S. (2012). Empathy with fictional stories: Reconsideration of the fantasy scale of the Interpersonal Reactivity Index. Psychological Reports, 110, 304-314.

Palacio, R. J. (2012). Wonder. New York, NY: Alfred A. Knopf.

Rowling, J. K. (1998-2007). Harry Potter series. New York, NY: Arthur A. Levine.

Stansfield, J., \& Bunce, L. (2014). The relationship between empathy and reading fiction: Separate roles for cognitive and affective components. Journal of European Psychology Students, 5(3), 9-18.

Van der Graaff, J., Branje, S., De Wied, M., Hawk, S., Van Lier, P., \& Meeus, W. (2014). Perspective taking and empathic concern in adolescence: Gender differences in developmental changes. Developmental Psychology, 50, 881-888.

Vezzali, L., Stathi, S., \& Giovannini, D. (2012). Indirect contact through book reading: Improving adolescents' attitudes and behavioral intentions toward immigrants. Psychology in the Schools, 49, 148-162.

Vezzali, L., Stathi, S., Giovannini, D., Capozza, D., \& Trifiletti, E. (2014). The greatest magic of Harry Potter: Reducing prejudice. Journal of Applied Social Psychology, 45, 105-121.

Walsh, C. (2013) Schoolyard scourge: Talk on bullying covers impact of technology, prevention efforts. Retrieved from http://news.harvard.edu/gazette/story/2013/03/schoolyardscourge/. 